\title{
Digital Image Analysis to Supplement Direct Measures of Lettuce Biomass
}

\author{
Natalie R. Bumgarner, Whitney S. Miller, \\ and Matthew D. Kleinhenz ${ }^{1}$
}

ADDITIONAL INDEX WORDS. nondestructive, remote sensing, Lactuca sativa, camera, WinCAM

Summary. Plant growth and biomass assessments are required in production and research. Such assessments are followed by major decisions (e.g., harvest timing) that channel resources and influence outcomes. In research, resources required to assess crop status affect other aspects of experimentation and, therefore, discovery. Destructive harvests are important because they influence treatment selection, replicate number and size, and the opportunity for true repeated measures. This work sought to establish the limits to which image acquisition and analysis may replace standard, destructive measures of fresh lettuce biomass. Outdoor, high tunnel, and greenhouse plantings of three cultivars of red and green leaf lettuce (Lactuca sativa) were direct-seeded in raised beds and plastic trays in spring, summer, and fall seasons in 2009-10 in Wooster, OH. Overhead images (624 in total) were captured at specific time points after seeding using handheld and tripodmounted commercial digital cameras. Fresh weight and leaf area of destructive plant samples within the digital images were also collected. Images were analyzed using user-defined settings in WinCAM software (Regent Instruments, Quebec, QC, Canada). A reference grid captured within each image allowed for the calculation of crop canopy cover (percent of two-dimensional image area covered by leaves). Calculations of canopy cover require differentiating leaves and rooting medium by color. The rooting medium was dark in color, and differentiating red leaves against this background was less reliable than differentiating green leaves from background. Nevertheless, in samples collected in the greenhouse 7 to 16 days after sowing (DAS), significant correlations $(v)$ of 0.85 to $0.96(P<0.05)$ were observed between measures of canopy cover calculated by image analysis software and leaf area obtained with a leaf area meter on harvested plant material. In outdoor and high tunnel plots 16 to 30 DAS, correlation coefficients between direct measures of plant biomass and WinCAM estimates of canopy cover were 0.71 to $0.95(P<0.0001)$. We conclude that digital image analysis may be useful in real-time, nondestructive assessments of early stage leaf lettuce canopy development, particularly when the leaf area index (LAI) is less than one and settings are dominated by green leaves.

$\mathrm{C}$ rop production and research involve descriptions and predictions of plant growth and biomass accumulation and distribution. Both processes involve destructive and nondestructive sampling. Destructive sampling is most common and typically precedes direct Horticulture and Crop Science, The Ohio State
University-OARDC, Wooster, OH 44691

Salaries and research support provided in part by State and Federal funds appropriated to the Ohio Agricultural Research and Development Center, The Ohio State University. Work also supported in part by the OARDC Research Internship Program and grants from the Ohio Vegetable and Small Fruit Research and Development Program.

Critical reading of this manuscript by Peter Ling and Robert Hansen and technical assistance by Jeffery West as well as material support by Shamrock Seeds and AT Films are gratefully acknowledged.

Use of trade names does not imply endorsement of the products named nor criticism of similar ones not named.

${ }^{1}$ Corresponding author. E-mail: kleinhenz.1@osu.edu. measures of many variables. Still, direct sampling consumes time, effort, crop tissue, space, and other resources. It may also produce misleading results, such as inaccurate estimates extrapolated from subsample biomass values (Catchpole and Wheeler, 1992; Im and Jensen, 2008). Destructive sampling also tends to disrupt repeated measures of experimental plants or plots through time (Baker et al., 1996; Casadesus et al., 2007; Tucker, 1980). Reliable, resource-saving tools are required to enhance the effectiveness of destructive sampling in commercial and research settings.

Nondestructive assessment methods (e.g., remote sensing), which rely on estimates made without destroying or removing tissue, are an alternative for scientists and producers. Remote sensing includes photography, machine vision, thermal imaging, laser scanning, and multispectral imaging. Regardless of form, the use of remote sensing for nondestructive assessment of plants and canopies is increasingly common in agriculture, ecology, and research. Photography, using film and digital formats, is one of the most common, versatile, and cost-effective methods of nondestructively gathering information on a variety of crops (Campbell, 2002; Casadesus et al., 2007; Gerard et al., 1997; Hunt et al., 2011; Klassen et al., 2003; Stewart et al., 2007; Yang et al., 2009). Still, estimates made via remote sensing and other approaches to nondestructive assessment are often adjusted based on validated measures or models built from on-site duplicate sampling or ground-truthing (Catchpole and Wheeler, 1992; Hatfield et al., 2008; Im and Jensen, 2008).

Digital images are gathered with various types of equipment. Inexpensive, consumer-based digital cameras capture wide bands of reflected light primarily in the blue, green, and red regions. Hyper- or multispectral, special-use cameras capture a wider portion of the spectrum, more narrow wavebands within the spectrum, or both (Hunt et al., 2011; Li et al., 2010; Trout et al., 2008; Yang et al., 2009). Image analysis typically follows acquisition, regardless of method, and often involves software. Like cameras, image analysis software includes common-use commercially available

\begin{tabular}{lllc}
\hline $\begin{array}{l}\text { Units } \\
\text { To convert U.S. to SI, } \\
\text { multiply by }\end{array}$ & U.S. unit & SI unit & $\begin{array}{l}\text { To convert SI to U.S., } \\
\text { multiply by }\end{array}$ \\
\hline 0.3048 & $\mathrm{ft}$ & $\mathrm{m}$ & 3.2808 \\
0.0929 & $\mathrm{ft}^{2}$ & $\mathrm{~m}^{2}$ & 10.7639 \\
2.54 & inch $(\mathrm{es})$ & $\mathrm{cm}$ & 0.3937 \\
25.4 & inch $(\mathrm{es})$ & $\mathrm{mm}$ & 0.0394 \\
0.0254 & $\mathrm{mil}$ & $\mathrm{mm}$ & 39.3701 \\
28.3495 & $\mathrm{Oz}$ & $\mathrm{g}$ & 0.0353 \\
305.1517 & $\mathrm{oz} / \mathrm{ft}^{2}$ & $\mathrm{~g} \cdot \mathrm{m}^{-2}$ & 0.0033 \\
$\left({ }^{\circ} \mathrm{F}-32\right) \div 1.8$ & ${ }^{\circ} \mathrm{F}$ & ${ }^{\circ} \mathrm{C}$ & $\left(1.8 \times{ }^{\circ} \mathrm{C}\right)+32$
\end{tabular}


and project-specific programs. Image analysis publications have listed these software programs: Photoshop [Adobe Systems, San Jose, CA (Aide et al., 2007; Klassen et al., 2003; Stewart et al., 2007)], GIMP 2.2 and Image J 1.33 freeware (Campillo et al., 2008), MATLAB [MathWorks, Natick, MA (Lati et al., 2011; Rasmussen et al., 2007)], ENVI [ITT Visual Information Solutions, Boulder, CO (Hunt et al., 2011)], Sigma Scan [Systat Software, Chicago (Olmstead et al., 2001, 2004)], and WinCAM [Regent Instruments, Quebec, QC, Canada (Chai et al., 2010; Mkandawire et al., 2005; Roturier and Bergsten, 2009)].

Image analysis is reported to be effective in assessing vegetative cover, nutrient status, crop maturity, and vegetation indices in many agronomic and forage crops (Adamsen et al., 1999; Casadesus et al., 2007; Gerard et al., 1997; Li et al., 2010; Lukina et al., 1999; Olmstead et al., 2004; Stewart et al., 2007). Image analysis has also proven useful in describing weed populations and plant diseases (Lamb and Weedon, 1998; Lati et al., 2011; Neeser et al., 2000; Ngouajio et al., 1999; Nilsson, 1995). Digital images are used in ecology to monitor plant- or landscape-level changes (Booth and Cox, 2008; Ide and Oguma, 2010). Image assessment and other methods of remote sensing have been used in horticultural crop applications (Campillo et al., 2008; Davenport et al., 2005; Yang et al., 2008), although further investment in techniques and applications are needed (Lee et al., 2010; Trout et al., 2008).

With testing and calibration, nondestructive sampling (e.g., image acquisition and analysis using commercially available equipment and software) may effectively supplement or replace scientific destructive sampling in horticultural crop production. Digital image analysis has often been tested and optimized with the use of sophisticated or proprietary image manipulation tools, algorithms, or both that may be better suited to research than production settings (Adamsen et al., 1999; Lati et al., 2011; Rasmussen et al., 2007). Ease of use, cost, utility, and accuracy are important considerations in the development of nondestructive assessment methods regardless of application (Adamsen et al., 1999; Aide et al., 2007; Hatfield et al., 2008). Overall, digital image acquisition and analysis must be repeated under a range of conditions to establish the limits of their application.

We grew leaf lettuce in outdoor, high tunnel, and greenhouse settings and used commercially available cameras and software to acquire and analyze digital images of these crops at various stages. Our goal was to document relationships between calculated values of crop variables obtained via this nondestructive approach and values obtained via destructive sampling and direct measurement. We also aimed to identify steps in the image acquisition and analysis process where these relationships are weakened.

\section{Materials and methods}

CASE STUDY $1:$ EIGHT MICROCLIMATE-CULTIVAR COMBINATIONS IN OUTDOOR AND HIGH TUNNEL SETTINGS. This study consisted of experimentally altered microclimates in duplicate outdoor and high tunnel settings in two spring and one fall season (2009-10) at the Ohio Agricultural Research and Development Center (OARDC) in Wooster, OH, as reported by Bumgarner et al. (2011). High tunnel experiments were carried out in a single $30 \times 80 \times 13$-ft singlebay, gothic style, single-layer, 6-mil high tunnel, while outdoor experiments were in an immediately adjacent open field. Both experiments consisted of split-plot designs with the four microclimate and two cultivar treatments functioning as main and subplot factors, respectively. The eight microclimate $\times$ cultivar treatment combinations were replicated four times in each experiment. Eight wood-framed raised beds $(2 \mathrm{ft} \times 8 \mathrm{ft} \times 6$ inches $)$ contained the four main plot microclimates: 1) unheated and uncovered control, 2) subsurface heated with soil heating cable, 3) aerial covered with low tunnel, and 4) subsurface heated and aerial covered. Four subplots $(2 \times$ $2 \mathrm{ft}$ ) containing the two tested lettuce cultivars were contained within each main plot. Control plots consisted of unheated and uncovered raised beds. Subsurface heated treatments contained a 40-ft automatic electric heating cable (Wrap-On Co., Bedford Park, IL) at $\approx 4$ inches depth, triggered to function at temperatures below $23{ }^{\circ} \mathrm{C}$, to provide root-zone heating. Aerial covered main plots were covered by a single layer low tunnel of slitted 0.8 -mil polyethylene plastic (Hummert International, Earth City, MO).

The growing medium consisted of $(\mathrm{v} / \mathrm{v}) 35 \%$ peatmoss (Premier Horticulture, Quakerstown, PA), 35\% dairy manure compost (OARDC), $15 \%$ shredded organic red clover (Trifolium pratense) hay (OARDC), and $15 \%$ silt loam field soil (OARDC). About 1000 preweighed primed and pelleted seeds of the two red leaf romaine lettuce cultivars [Outredgeous (Johnny's Selected Seeds, Winslow, ME) and Flagship (Shamrock Seeds, Salinas, CA)] were sown on 21 Mar. and 10 Oct. 2009, and 16 Mar. 2010 in seven parallel rows within each plot.

Digital images $(3264 \times 2448$ pixels) of a $1-\mathrm{ft}^{2}$ quadrant in the center of each plot were gathered in the field using a handheld camera with a focal length of 6.3 to $18.9 \mathrm{~mm}$ (FE-360; Olympus Corp., Tokyo) positioned directly above the plot at a distance of $\approx 2 \mathrm{ft}$. Camera aperture and focus were placed on the automatic setting to prevent variable operatorinfluenced focus adjustments, and the flash was turned off. The camerasubject distance and viewing angle was standardized across images as much as possible. Images (576 in total) were collected $\approx 16,23$, and 30 DAS and acquisition was followed by destructive sampling in each plot. Destructive sampling (10 inches of random row) included removal of all plants followed by counting and weighing the whole sample before measuring shoot and root weight of a representative subsample. Final yield data were taken on a standardized $2-\mathrm{ft}^{2}$ section of each plot $\approx 30$ DAS.

Case Study 2: greenhouse SETTING. Leaf lettuce was produced in a $400-\mathrm{ft}^{2}$, glass greenhouse room in the Horticulture and Crop Science greenhouse facility in Summer 2009 at the OARDC in Wooster, OH. Destructive fresh shoot biomass and leaf area measurements were compared with analyzed digital images across several time points of plant growth. 'Outredgeous', a red-leaf romaine lettuce, and green leaf 'Two-Star' were used to ensure measurements varying in leaf color and shape and plant growth habit. Half flats $[11 \times 11$ inches (BFG Supply, Burton, OH)] were filled with moistened media (Pro-Mix BX; Premier Horticulture), 
and $\approx 180$ primed and pelleted seeds were placed by hand in three parallel rows at 3 -inch spacing on 24 June 2009. Four replicate flats of each cultivar, one in each of the four blocks, were seeded for harvest at each of the six harvest dates for a total of 48 flats. Harvest date of each flat was randomized within each block.

Digital images $(3648 \times 2736$ pixels) of all flats were gathered in the greenhouse using a commercial camera with a 36 to $216 \mathrm{~mm}$ focal length (Powershot A2000; Canon USA, Lake Success, NY). Images were generally taken between 13:00 and 16:00 HR using a stationary tripod at a vertical distance of $\approx 30$ inches and a consistent camera angle. Camera aperture and focus were placed on the automatic setting to prevent variable, operator-influenced focus adjustments, and the flash was turned off. Images (48 in total) were taken $7,10,14,16,21$, and 28 DAS to correspond to preharvest destructive samples and the final harvest. Destructive plant data were also collected on the center of three rows in each half flat at each harvest date. The center row of each flat was removed by hand, roots were washed to remove media particles, whole plants were counted and weighed as a group, and shoot and root fresh weights were recorded for a representative subsample. Shoot leaf subsamples were then measured with a leaf area meter (LI-3100C; LI-COR Biosciences, Lincoln, NE). These procedures were duplicated at each harvest $7,10,14,16$, and 21 DAS. For the final harvest date at $28 \mathrm{DAS}$, digital images were captured, and plants in the center row of each flat were harvested just above media level to represent leaf lettuce fresh shoot biomass yield.

Digital image analysis. Image analysis was carried out using WinCAM 2009 Regular, which is designed to estimate specified colored regions in images. Images were saved from the camera onto a desktop computer (Optiplex GX270 $2.6 \mathrm{GHz}$; Dell, Round Rock, TX) as JPEG files. The analyzed region of each image was standardized for analysis to include only the area inside the $1-\mathrm{ft}^{2}$ quadrant or the $11 \times 11$-inch half flat. Operator-assisted color selection was used to designate colors in the image as background or leaf by selecting a specific set of colors from within the image to define color classes. All pixels chosen in the color class as leaf were used in the leaf calculation, while all other pixels were classified as background color by WinCAM. The percentage of pixels was then used to calculate canopy cover compared with the area of media background in every image (Figs. 1 and 2). The accuracy of the software program was also assessed by comparing digitally traced and uniformly colored outlines of the total plant cover in a subset of selected images in Photoshop before analysis with WinCAM. These manually enhanced high contrast images were used as a reference leaf area in the image and were compared with the same raw image analyzed by WinCAM (Fig. 3).

Data Analysis. Analysis by Proc Corr (SAS version 9.2; SAS Institute, Cary, NC) was employed specifically to describe relationships between data collected on leaf lettuce crops using destructive and nondestructive approaches. Overall, destructive plant measures and WinCam estimates of canopy cover from 624 digital images in outdoor, high tunnel, and greenhouse settings were correlated (Tables 1 and 2 ), providing opportunities for further more specific study. In the outdoor and high tunnel settings, biomass yield data (Bumgarner et al., 2011) and WinCAM canopy cover estimates collected $\approx 30$ DAS were analyzed separately within each experiment to uncover the ability of the image analysis method to describe potential treatment effects on growth (Table 3). A Proc Univariate procedure was carried out on all data to test for normality. All data were analyzed in Proc Mixed. Data with a non-normal distribution were natural log transformed before analysis and then back transformed for inclusion in tables. Microclimate and cultivar were analyzed as fixed effects, and replications within years were analyzed as random effects in Proc Mixed. Treatment means were separated using a pdiff difference statement at a $P<0.05$ level of significance when microclimate and cultivar fixed effects were significant at $P<0.05$.

\section{Results}

Relationships between calculated values of crop variables obtained via a nondestructive image acquisitionanalysis approach and values obtained via destructive sampling and direct measurement were tested using correlation. Correlations were significant
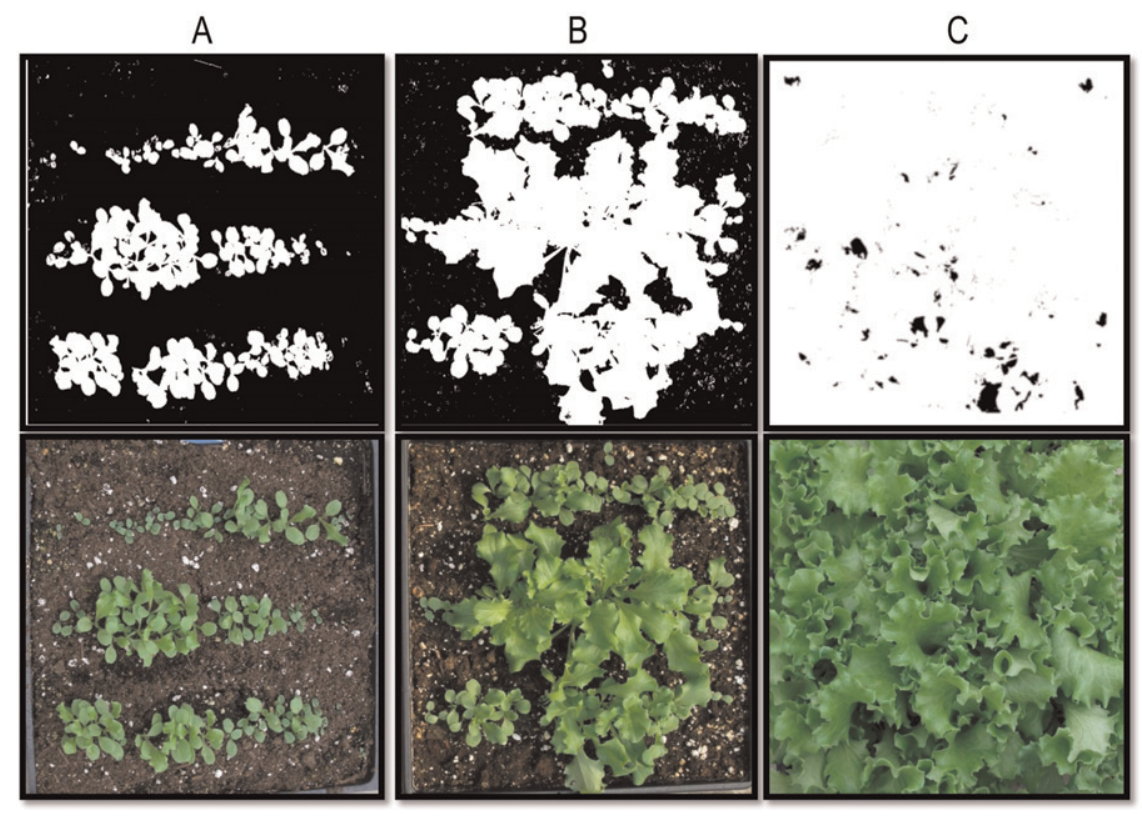

Fig. 1. Black and white images (top row) illustrating WinCAM (Regent Instruments, Quebec, QC, Canada) identification of leaf (white) or background (black) material paired with original digital images in greenhouse-grown 'TwoStar' leaf lettuce (A) $10 \mathrm{~d}$ after seeding (DAS) [ $20 \%$ canopy cover (CC), $9.8 \mathrm{~g}$ fresh shoot weight (FSW), 30.5 inch $^{2}$ leaf area (LA)], (B) 16 DAS (48\% CC, $31.6 \mathrm{~g} \mathrm{FSW,}$ $\left.156.9 \mathrm{inch}^{2} \mathrm{LA}\right)$, and (C) $28 \mathrm{DAS}$ (97\% CC, $145.1 \mathrm{~g} \mathrm{FSW,} 963.0$ inch $\left.^{2} \mathrm{LA}\right)$; $1 \mathrm{~g}=0.0353 \mathrm{oz}, 1 \mathrm{inch}^{2}=6.4516 \mathrm{~cm}^{2}$. 

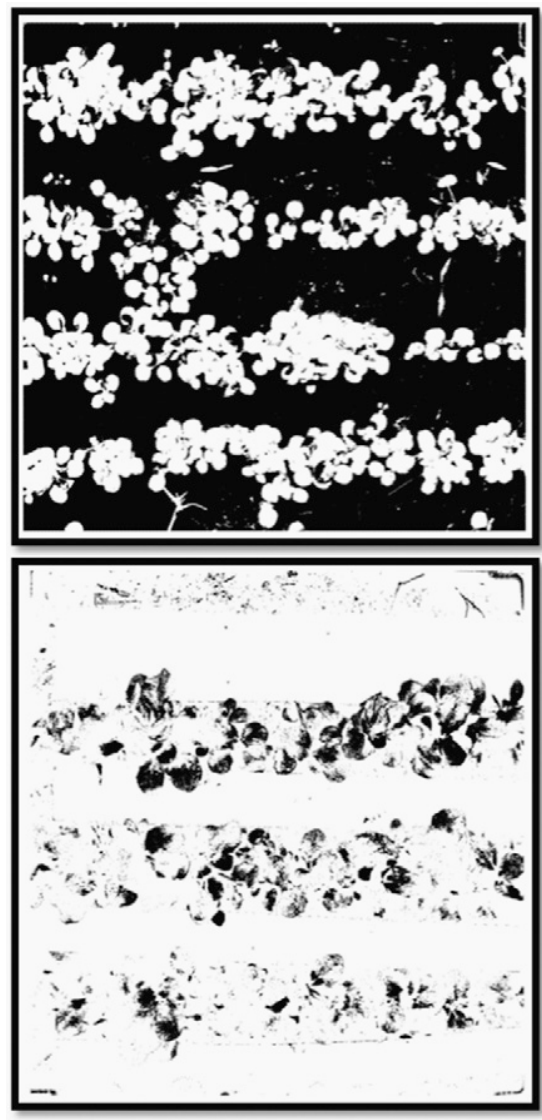

Fig. 2. Black and white images illustrating WinCAM (Regent Instruments, Quebec, QC, Canada) identification of digital images of high tunnel-grown 'Outredgeous' leaf lettuce with (top) primarily green leaves where separation between leaf (white) and background (black) material was relatively efficient, and (bottom) 'Flagship' leaf lettuce with primarily red leaves where separation between leaf (black) and background (white) material was less efficient.

and positive at all time points in the outdoor and high tunnel experiments (Table 1, Case Study 1) and at five of six time points in the greenhouse experiment (Table 2, Case Study 2). Plant age did not consistently impact correlations within Case Study l (outdoor, high tunnel), but age was a factor in Case Study 2 (greenhouse). Analysis of variance (ANOVA) of microclimate treatment effects outdoors and in the high tunnel at $\approx 30$ DAS using data from analyzed digital images (Table 3 ) was often similar to analysis using fresh biomass data. However, leaf color (cultivar-based) also emerged as a factor that can influence the reliability and efficiency of digital images used as a partial proxy for direct measurement.

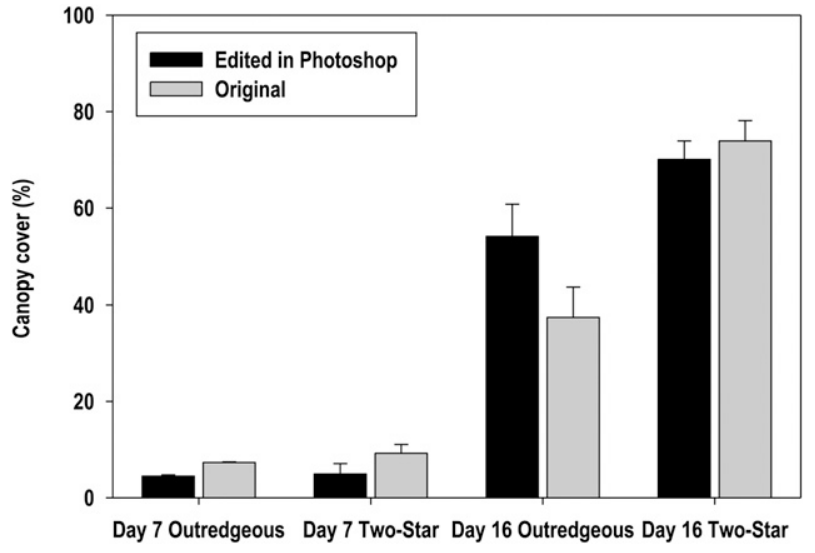

Fig. 3. Potential impact of cultivar and age on separation of leaf and background material in 'Outredgeous' red leaf lettuce and 'Two-Star' green leaf lettuce in an outdoor summer experiment as illustrated by the canopy cover $( \pm S E)$ as classified by the WinCAM software program (Regent Instruments, Quebec, QC, Canada) with and without editing in Photoshop (Adobe Systems, San Jose, CA); $n=2$.

Case Study 1. Pearson correlation coefficients between shoot fresh biomass measurements taken at $\approx 16$, 23 , and 30 DAS and digital image canopy cover estimates were significant for both the outdoor and high tunnel settings in all experiments (Table 1). When both cultivars were included in each analysis $(N=32)$, correlations were 0.71 to 0.95 outdoors and 0.72 to 0.85 in the high tunnel. Time points with the highest correlation coefficients varied by experiment, and no consistent trend between correlations and DAS was detected. While correlations were slightly lower in the high tunnel than in outdoor plots overall, results in both settings were similar. While correlations were significant at all time points in all experiments, correlations across all sampling points tended to be strongest in Spring 2009 in both settings.

Correlations between direct measures of fresh shoot biomass and estimates of canopy cover from image analysis were also calculated on a cultivar-specific basis (Table 1$)$. Correlations were significant $(P<0.05)$ at all points of measurement and major trends tended to hold for both cultivars. Outdoors, correlations for 'Outredgeous' were stronger at all sampling points in all three experiments (Table 1). Numerically, correlations between destructive and nondestructive measures outdoors were greater for 'Outredgeous' alone than for the average of the two cultivars although fewer observations $(N=16)$ were included in the single-cultivar analysis
(Table 1). Similar trends were observed in the high tunnel but less consistently and in a manner mediated by season.

A second approach involving preexisting data and images was also used to describe relationships between direct and indirect measures of biomass. Specifically, we set out to determine if the outcomes of image analysis after the fact resembles outcomes obtained previously via destructive sampling and direct measurement. Would image analysis arrive at the same treatment effects on plant biomass as previous direct measurement? ANOVA was completed to address this question, the answer to which appears to be "yes" under these conditions (Table 3 ). Significant treatment effects on direct measures of biomass and indirect measures of canopy cover were noted in all six experiments. Trends in treatment means separation outcomes were similar between direct and indirectly obtained estimates of biomass, particularly in the outdoor setting. However, cultivar effects were similar between approaches in only three of six experiments.

Case Study 2. Destructive:nondestructive measure correlations were positive and significant at five of six time points in the greenhouse experiment (Table 2). However, plant age had a stronger influence on these correlations when tested in the greenhouse than when tested in outdoor or high tunnel settings. For example, in the greenhouse, correlations were strongest 14 DAS and decreased thereafter, showing as not significant 
Table 1. The relationship between canopy cover (CC) from WinCAM (Regent Instruments, Quebec, QC, Canada) analyzed digital images and fresh shoot weight (FSW) from destructive harvests of 'Outredgeous' (Out) and 'Flagship' (Flag) leaf lettuce in spring and fall outdoor and high tunnel experiments (Case Study 1) in 2009-10 in Wooster, OH.

\begin{tabular}{|c|c|c|c|c|c|c|c|c|c|}
\hline & \multicolumn{3}{|c|}{ Spring 2009} & \multicolumn{3}{|c|}{ Fall 2009} & \multicolumn{3}{|c|}{ Spring 2010} \\
\hline & Out + Flag $^{\mathrm{z}}$ & Out $^{\mathrm{y}}$ & Flag $^{y}$ & Out + Flag & Out & Flag & Out + Flag & Out & Flag \\
\hline \multicolumn{10}{|c|}{ Correlation coefficient $(P \text { value })^{x}$} \\
\hline \multicolumn{10}{|c|}{ Outdoor } \\
\hline Day 16 & 0.91 & 0.95 & 0.86 & 0.71 & 0.95 & 0.68 & 0.84 & 0.88 & 0.79 \\
\hline CC:FSW & $(<0.0001)$ & $(<0.0001)$ & $(<0.0001)$ & $(<0.0001)$ & $(<0.0001)$ & $(0.0039)$ & $(<0.0001)$ & $(<0.0001)$ & $(0.0003)$ \\
\hline Day 23 & 0.90 & 0.91 & 0.88 & 0.82 & 0.94 & 0.69 & 0.89 & 0.93 & 0.69 \\
\hline CC:FSW & $(<0.0001)$ & $(<0.0001)$ & $(<0.0001)$ & $(<0.0001)$ & $(<0.0001)$ & $(0.0041)$ & $(<0.0001)$ & $(<0.0001)$ & $(0.0032)$ \\
\hline Day 30 & 0.87 & 0.89 & 0.85 & 0.95 & 0.98 & 0.96 & 0.87 & 0.89 & 0.72 \\
\hline CC:FSW & $(<0.0001)$ & $(<0.0001)$ & $(<0.0001)$ & $(<0.0001)$ & $(<0.0001)$ & $(<0.0001)$ & $(<0.0001)$ & $(<0.0001)$ & $(0.0016)$ \\
\hline \multicolumn{10}{|c|}{ High tunnel } \\
\hline Day 16 & 0.85 & 0.91 & 0.77 & 0.80 & 0.84 & 0.81 & 0.75 & 0.76 & 0.85 \\
\hline CC:FSW & $(<0.0001)$ & $(<0.0001)$ & $(0.0005)$ & $(<0.0001)$ & $(<0.0001)$ & $(0.0001)$ & $(<0.0001)$ & $(0.0006)$ & $(<0.0001)$ \\
\hline Day 23 & 0.77 & 0.77 & 0.76 & 0.83 & 0.93 & 0.79 & 0.78 & 0.83 & 0.75 \\
\hline CC:FSW & $(<0.0001)$ & $(0.0006)$ & $(0.0006)$ & $(<0.0001)$ & $(<0.0001)$ & $(0.0003)$ & $(<0.0001)$ & $(<0.0001)$ & $(0.0009)$ \\
\hline Day 30 & 0.80 & 0.91 & 0.77 & 0.72 & 0.81 & 0.65 & 0.81 & 0.81 & 0.90 \\
\hline CC:FSW & $(<0.0001)$ & $(<0.0001)$ & $(0.0005)$ & $(<0.0001)$ & $(0.0002)$ & $(0.0061)$ & $(<0.0001)$ & $(0.0001)$ & $(<0.0001)$ \\
\hline
\end{tabular}

Table 2. The relationship between canopy cover (CC) from WinCAM (Regent Instruments, Quebec, QC, Canada) analyzed digital images, fresh shoot weight (FSW) and leaf area (LA) from destructive harvests of 'Outredgeous' and 'Two-Star' lettuce in a summer greenhouse experiment (Case Study 2) in 2009 in Wooster, OH.

\begin{tabular}{|c|c|c|c|c|c|c|c|c|c|}
\hline & Day $7^{\mathrm{z}}$ & Day $10^{\mathrm{z}}$ & Day $14^{z}$ & Day $16^{z}$ & Day $21^{\mathrm{z}}$ & Day $28^{z}$ & Day $7-28^{y}$ & $\begin{array}{c}\text { 'Outredgeous' } \\
\text { Day } 7-28^{\mathrm{x}}\end{array}$ & $\begin{array}{l}\text { 'Two-Star' } \\
\text { Day 7-28 }\end{array}$ \\
\hline & \multicolumn{9}{|c|}{ Correlation coefficient ( $P$ value $)^{\mathrm{w}}$} \\
\hline CC:FSW & $\begin{array}{l}0.84 \\
(0.0084)\end{array}$ & $\begin{array}{l}0.87 \\
(0.0055)\end{array}$ & $\begin{array}{l}0.95 \\
(0.0004)\end{array}$ & $\begin{array}{l}0.84 \\
(0.0096)\end{array}$ & $\begin{array}{l}0.77 \\
(0.026)\end{array}$ & $\begin{array}{c}0.22 \\
(0.60)\end{array}$ & $\begin{array}{c}0.86 \\
(<0.0001)\end{array}$ & $\begin{array}{c}0.78 \\
(<0.0001)\end{array}$ & $\begin{array}{c}0.90 \\
(<0.0001)\end{array}$ \\
\hline
\end{tabular}

${ }^{2} N=8$.

${ }^{\mathrm{y}} \mathrm{N}=48$.

${ }^{x} N=24$.

"Pearson correlation coefficient $(r)$ followed by probability value in parentheses.

28 DAS (Table 3 ). Correlations in the greenhouse were moderately influenced by cultivar leaf color and morphology and plant growth habit with 'Two-Star' WinCAM:destructive harvest correlations tending to be higher than those of 'Outredgeous'. However, cultivar effects of both leaf color and morphology and plant form appeared to be diminished in the summer greenhouse study relative to fall and spring outdoor and high tunnel settings where leaf color was the main difference between cultivars.

\section{Discussion}

In digital image analysis, samples are comprised of two-dimensional images representing three-dimensional objects. Plant canopies such as those studied here include both visible or emergent and hidden or occluded leaves. We sought to assess the strength of the association between leaf and biomass data obtained via nondestructive digital image analysis and related data obtained through standard destructive means. The strength of that association hinges on the extent to which two-dimensional images represent three-dimensional canopies. The data suggest that the association may be strong enough to warrant further attention in research and other settings. More specifically, the data suggest that digital image acquisition and analysis may be a suitable replacement for or supplement to destructive sampling and direct measurement of leafy vegetable crop canopies provided cultivar-background color contrast, growth setting, and plant age do not interfere. Correlations between direct measures of lettuce leaf biomass taken on harvested plant samples and indirect measures obtained with a camera and software were consistent and statistically significant. This major result held for crops of tested cultivars grown in a range of conditions established in outdoor, high tunnel, and greenhouse settings in spring, fall, and summer seasons.

In research, these correlations suggest that fewer resources (e.g., seed, space, crop inputs) may be required to document treatment effects, 
Table 3. Lettuce fresh shoot weight (FSW) from destructive harvest and canopy cover (CC) as estimated using WinCAM (Regent Instruments, Quebec, QC, Canada) digital image analysis $\approx \mathbf{3 0} \mathrm{d}$ after sowing in two red romaine cultivars exposed to four experimental microclimates in six outdoor and high tunnel experiments in 2009-10 in Wooster, OH.

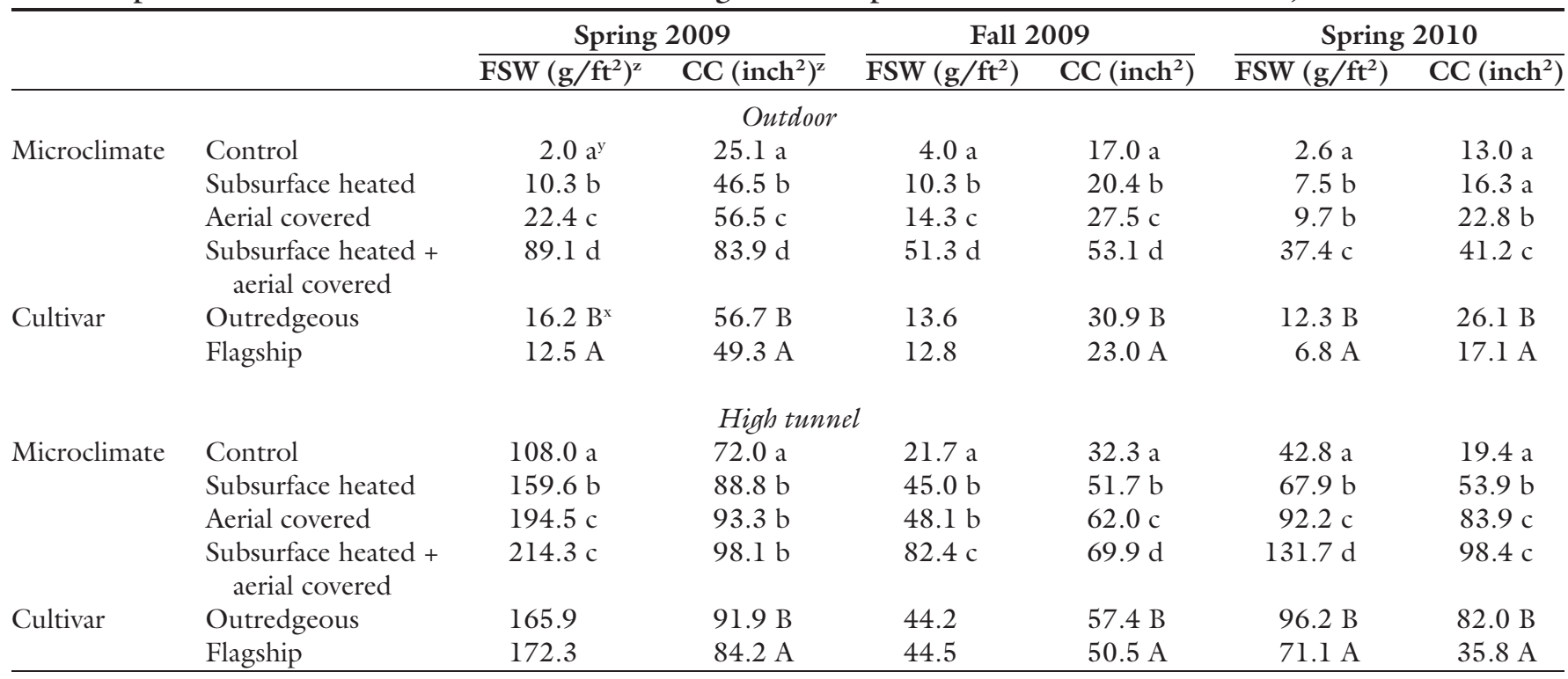

${ }^{2} \mathrm{lg} / \mathrm{ft}^{2}=10.7639 \mathrm{~g} \cdot \mathrm{m}^{-2}=0.0353 \mathrm{oz} / \mathrm{ft}^{2}, \mathrm{l}$ inch $^{2}=6.4516 \mathrm{~cm}^{2}$

${ }^{y}$ Means within columns and microclimates (lowercase letters) or cultivars (uppercase letters) followed by the same letter are not significantly different as separated by a pdiff difference statement at $P<0.05$ (SAS version 9.2 ; SAS Institute, Cary, NC).

that the benefits of repeated sampling can be realized more often, and that new hypotheses can be tested. In commercial production, these correlations suggest that yield models that aid scheduling and other processes may be developed, as reported previously (Kleinhenz and Radovich, 2003; Radovich and Kleinhenz, 2004). Results reported here also suggest that image acquisition and analysis be considered more seriously, particularly as improved hardware and software become available and as the need for efficiency increases in all sectors. That said, there is a wealth of opportunity and need with regard to follow-up related research designed to facilitate the greater application of digital image acquisition and analysis as outlined here.

\section{Image acquisition}

InSTRUMENTATION. Cameras vary in cost, performance, and ease of use, so the ideal camera type will vary with application. We tested the utility of images acquired with commercial digital cameras, which may appeal to scientists and farmers because of cost, availability, and features. This type of camera has assets but may have limits in measured wavebands and some parameters of color (Casadesus et al., 2007; Hunt et al., 2011) relative to specialized multi- or hyperspectral units that others may prefer. Comparing cameras or types of cameras was beyond the scope of this work, but the relative benefits of various units for use in the process described here should be explored. Potential users will likely prefer a balance of key features.

ENVIRONMENTAL AND PLANT CONDITIONS. Controlling for or overcoming ambient environmental conditions can be challenging in remote sensing, regardless of the instrument(s) used (Baker et al., 1996; Hack, 1989; Lati et al., 201 1; Lukina et al., 1999; Rasmussen et al., 2007; Tucker, 1980). For example, cloud cover exhibits a high level of spatiotemporal variation and complicates image acquisition and analysis. Controlling for cloud cover has involved numerous improvements in equipment, software, and process over time. In the two case studies described here, images were collected under spring, summer, and fall conditions in a temperate climate but on an experimental plan based on crop stage. There was comparatively little freedom in altering sampling date (e.g., per sky conditions). Case Study 1 was carried out in spring and fall when light levels varied. Shadows were occasionally present during image acquisition and difficult to avoid. Shadows were also occasionally visible in the data images and difficult to correct at the analysis stage using software and methods employed here. Case Study 2 was completed in a relatively constant, high light environment (summer greenhouse room) and presented fewer shadow issues than observed in the field and high tunnel.

Ambient conditions, especially light, complicate the use of image acquisition and analysis by scientists and field production personnel. Supplemental lighting was unavailable in Case Study l (outdoor, high tunnel). Also, use of the camera flash, when tried experimentally, further reduced contrast in images as bright sunlight may due to glare (Lukina et al., 1999). To reduce experimental error, images for each experiment were analyzed and compared separately by time point rather than between time points. This step standardized the impact of ambient light conditions and eliminated the need to calibrate for light conditions across time (Hunt et al., 2011). This approach is not optimum for all users, especially farmers and field managers. Follow-up efforts may benefit from including portable illumination to standardize light conditions and reduce the need for complicated or time consuming adjustments during image analysis.

Plant status and stand must also be considered during image acquisition. Digital images quantify leaf 
cover as a percentage of image area; therefore, leaf orientation is important (Klassen et al., 2003). Leaf orientation is influenced by light and moisture conditions that vary in time and space. Not surprisingly, alteration of leaf angle in certain species can change the amount of canopy closure as a result of both environmental and diurnal change (Giacomelli et al., 1998; Mullen et al., 2006). Therefore, 1) images should be acquired at similar times of day for comparison across dates (Giacomelli et al., 1998), 2) plant populations should be even for reliable extrapolation from image canopy cover to larger field cropping areas, and 3 ) comparisons should be restricted to similar varieties to minimize genotype as a source of experimental error.

Camera angle and height. The outcomes of image analysis may also be affected by the orientation and height of the camera during image acquisition. Inconsistencies in orientation can lead to changes in pixel resolution in space within and between digital images (Lati et al., 2011). Two methods were employed in attempts to standardize camera orientation in this work: freehand in Case Study 1 and a tripod in Case Study 2. Additionally, all images were taken from stationary rather than moving camera locations. Concerns over camera orientation and light levels are often justified, but their influence on image analysis can be reduced by consistency (Rasmussen et al., 2007). Earlier work has also shown that increasing the distance at which images are taken, resulting in a larger field of view or larger surface area in each image, can reduce variability (Ngouajio et al., 1999). Here, images were gathered from distances that required no additional equipment. Future field application could incorporate techniques to increase area in images by increasing camera height. Regardless, taking specific steps to standardize camera orientation and evaluate height-resolution relationships before and during image acquisition is prudent.

\section{Image analysis}

Plant SIZE AND gROWTH EFFECT. Data reported here (e.g., Case Study 2 ) indicate that plant age, through its effect on canopy closure and LAI, can influence the relationship between digital image-based and direct estimates of biomass. Canopy closure tends to signal that LAI has reached one and that additional growth is unlikely to be captured in digital images and their analysis with the same reliability as during preclosure (Hack, 1989; Stewart et al., 2007). Thus, correlations as studied here are likely to weaken after canopy closure and LAI exceeds one, especially in the absence of crop differences because of experimental treatments. In response, some propose the use of side-view images for some plants (Baker et al., 1996; Tackenberg, 2007), either alone or in conjunction with overhead images. However, integrating data from two views is more complex and likely to appeal primarily to scientists. Repeated evaluation of indirectdirect biomass estimate relationshipsin target cropping systems, over specific time frames and as drawn with overhead images analyzed with improved commercial software-may be a suitable alternative for many.

Separation of BaCkground MATERIAL FROM LEAF MATERIAL. Image analysis relies on an adequate and consistent differentiation between plant material (leaf canopy) and soil or media background (Olmstead et al., 2004; Thomas et al., 1988), and a lack of contrast lowers the precision and potential utility of image analysis (Olmstead et al., 2001). In this work, canopy-soil separation at the analysis stage was occasionally inadequate. Growing media were dark colored and contrasted strongly only with green leaves (Figs. 1 and 2A), sometimes complicating the analysis of images of red leaf cultivars (Fig. 2B). Others (e.g., Trout et al., 2008) have faced the same challenge, especially if images were collected in low light.

Four methods were employed to enhance background-canopy contrast, two during image acquisition, and two during image analysis. First, during acquisition, solid blue paper strips were inserted between plant rows to limit background interference. This method enhanced backgroundcanopy contrast and saved time during analysis. Second, red and green lens filters were used in a series of test images. However, in our tests, the value of lens filters was reduced because ambient light levels were often insufficient and resulted in dark images that were difficult to analyze well. Third, during analysis, color settings were manually adjusted during processing in WinCAM for each set of "troublesome" images. Fourth, images were manually adjusted before analysis. Using Photoshop, blackout regions were inserted in images in between-row regions where background interference could occur. This process was completed on all images within a time point sample to limit bias. This method was effective when plants were small, but less effective as plant cover increased. It was also very time-consuming. Follow-up work would do well to identify constitutive steps or camera or software features that enhance background-canopy contrast. Time efficiency will likely be best achieved by reducing environmental and plant color interference before image acquisition. In this work, we concluded that improving the quality and consistency of acquired images is preferable to additional steps to improve image quality during analysis. These steps or features will significantly increase the appeal of image acquisition-analysis in research and crop production. Software and camera advances will likely increase the ability to differentiate canopies and backgrounds under varied conditions and reduce these challenges in the future (Lati et al., 2011; Stewart et al., 2007).

The impact of incomplete background-canopy separation by WinCAM on correlations was quantified by further analysis of a selected subset of images from an outdoor, summer experiment. Images varying in canopy size and leaf color were chosen, the canopies were manually colored blue in Photoshop (Adobe Systems), the edited images were reprocessed by WinCAM, and data from edited and unedited images were compared. While such editing would not be feasible on a large scale because of the time involved, manually coloring in leaf area in Photoshop provided a "control" necessary to describe potential error ranges in the analyzed digital images. This comparison was undertaken to enhance understanding of the influence of both leaf color and shape (cultivar effects) and plant age (size and LAI) on the accuracy of digital image analysis. Data in Fig. 3 help illustrate that plant age and leaf color may influence the accuracy of image analysis as conducted here. 
Overestimation of leaf area was more common on small, young canopies, especially when background-canopy differentiation was inadequate. Interestingly, in test images, levels of overestimation were similar in green- and red-leaved cultivars at early stages of crop development. As canopies increased, image accuracy varied more clearly by leaf color with green more accurately identified than red and the latter being underestimated because of misclassification of leaf area as background.

Data reported here provide additional proof of concept for the use of digital image analysis as a replacement for or supplement to destructive sampling and direct measurement. The process we employed may save little time when collecting certain individual data points, but it does offer other advantages. For example, destructive sampling and measurement often involves the desire to collect many paired data on often perishable samples and the use of shared equipment and time-sensitive procedures. Image acquisition-analysis can reduce the time spent and need for certain instruments at harvest by delaying the collection of certain data. An indirect, digital approach to the collection of leaf area or biomass data can also reduce the amount of sample needed and it should allow for repeated measures on identical plots and samples.

However, image acquisitionanalysis must be rapid and reliable to be widely adopted. Image analysis is now regarded as the process bottleneck, and it must become straightforward and "high throughput" to interest many scientists and crop managers. Simplifying and speeding acquisition-analysis in most horticultural settings will require improvements in software and hardware. In this study, $30 \mathrm{~s}$ were required to load and analyze each image, which was triggered by the operator after settings were established and completed using an average (for 2009) personal computer. WinCAM offers a batch analysis option that is likely to speed the accrual of data on many images, particularly if differences in background or other properties are subtle. We analyzed images separately to better track system performance when processing images of samples diverse in origin and to test specific hypotheses about the process.

In conclusion, inadequate leafbackground color differentiation limited the ease and reliability with which digital image acquisition and analysis substituted for destructive sampling and direct measure of lettuce leaf biomass. Nevertheless, correlations between direct and indirect estimates of biomass were high under a range of circumstances and image analysis led to statistical results closely resembling a standard harvest-weigh routine. Advances in equipment, software, and technique will increase the appeal of digital image acquisition-analysis routines as partial substitutes for standard routines in research and production. Similarly, if modeling, prediction, or both are goals, system scaling factors must be determined so that relative gains in real leaf area or biomass vs. those in calculated values can be identified and employed in formulae. These relative gains are unlikely to be linear in all cases.

\section{Literature cited}

Adamsen, F.J., P.J. Pinter, Jr., E.M. Barnes, R.L. LaMorte, G.W. Wall, S.W. Leavitt, and B.A. Kimball. 1999. Measuring wheat senescence with a digital camera. Crop Sci. 39:719-724.

Aide, C., M. Aide, P. Voelker, and K. Macke. 2007. Determining the relative canopy coverage with a digital image and Adobe Photoshop ${ }^{\circledR}$ : A pilot project to introduce a low cost technique. Trans. Mo. Acad. Sci. 41:20-25.

Baker, B., D.M. Olszyk, and D. Tingey. 1996. Digital image analysis to estimate leaf area. J. Plant Physiol. 148:530-535.

Booth, D.T. and S.E. Cox. 2008. Imagebased monitoring to measure ecological change in rangeland. Front. Ecol. Environ. 6:185-190.

Bumgarner, N.R., M.A. Bennett, P.P. Ling, R.W. Mullen, and M.D. Kleinhenz. 2011. Canopy cover and root-zone heating effects on fall- and spring-grown leaf lettuce yield in Ohio. HortTechnology 21:737-744.

Campbell, J.B. 2002. Introduction to remote sensing. 3rd ed. Guilford Press, New York.

Campillo, C., M.H. Prieto, C. Daza, M.J. Monino, and M.I. Garcia. 2008. Using digital images to characterize canopy coverage and light interception in a processing tomato crop. HortScience 43:1780-1786.
Casadesus, J., Y. Kaya, J. Bort, M.M. Nachit, J.L. Araus, S. Amor, G. Ferrazzano, F. Maalouf, M. Maccaferri, V. Martos, H. Ouabbou, and D. Villegas. 2007. Using vegetation indices derived from conventional digital cameras as selection criteria for wheat breeding in water-limited environments. Ann. Appl. Bot. 150:227236.

Catchpole, W.R. and C.J. Wheeler. 1992. Estimating plant biomass: A review of techniques. Aust. J. Ecol. 17:121-131.

Chai, Q., X. Shao, and J. Zhang. 2010. Silicon effects on Poa pratensis responses to salinity. HortScience 45:1876-1881.

Davenport, J.R., E.M. Perry, N.S. Lang, and R.G. Stevens. 2005. Leaf spectral reflectance for nondestructive measurement of plant nutrient status. HortTechnology 15:31-35.

Gerard, B., A. Buerkert, P. Hiernaux, and H. Marschner. 1997. Non-destructive measurement of plant growth and nitrogen status of pearl millet with low-altitude aerial photography. Soil Sci. Plant Nutr. 43:993-998.

Giacomelli, G.A., P.P. Ling, and J. Kole. 1998. Determining nutrient stress in lettuce plants with machine vision. HortTechnology 8:361-365.

Hack, G.R. 1989. The use of image processing under greenhouse conditions for growth and climate control. Acta Hort. 245:455-461.

Hatfield, J.L., A.A. Gitelson, J. Schepers, and C.L. Walthall. 2008. Application of spectral remote sensing for agronomic decisions. Agron. J. 100:117-131.

Hunt, E.R., Jr., W.D. Hively, G.W. McCarty, C.S.T. Daughtry, P.J. Forrestal, R.J. Kratochvil, J.L. Carr, N.F. Allen, J.R. Fox-Rabinovitz, and C.D. Miller. 2011. NIR-green-blue high-resolution digital images for assessment of winter cover crop biomass. GIsci. Remote Sens. 48: 86-98.

Ide, R. and H. Oguma. 2010. Use of digital cameras for phenological observations. Ecol. Inform. 5:339-347.

Im, J. and J.R. Jensen. 2008. Hyperspectral remote sensing of vegetation. Geography Compass 26:1943-1961.

Klassen, S.P., G. Ritchie, J.M. Frantz, D. Pinnock, and B. Bugbee. 2003. Real-time imaging of ground cover: Relationships with radiation capture, canopy photosynthesis, and daily growth rate. Amer. Soc. Agron. Spec. Publ. 66:3-15.

Kleinhenz, M.D. and T.J.K. Radovich. 2003. Rapid, accurate, in-field estimation of cabbage crop marketable yield. Acta Hort. 628:111-118. 
Lamb, D.W. and M. Weedon. 1998. Evaluating the accuracy of mapping weeds in fallow fields using airborne digital imaging: Panicum effusum in oilseed rape stubble. Weed Res. 38:443-451.

Lati, R.N., S. Filin, and H. Eizenberg. 2011. Robust methods for measurement of leaf-cover area and biomass from image data. Weed Sci. 59:276-284.

Lee, W.S., V. Alchanatis, C. Yang, M. Hirafuji, D. Moshou, and C. Li. 2010. Sensing technologies for precision specialty crop production. Comput. Electron. Agr. 74:2-33.

Li, Y., D. Chen, C.N. Walker, and J.F. Angus. 2010. Estimating the nitrogen status of crops using a digital camera. Field Crops Res. 118:221-227.

Lukina, E.V., M.L. Stone, and W.R. Raun. 1999. Estimating vegetation COVerage in wheat using digital images. J. Plant Nutr. 22:341-350.

Mkandawire, M., B. Taubert, and E.G. Dudel. 2005. Resource manipulation in uranium and arsenic attenuation by Lemna gibba L. (duckweed) in tailing water of a former uranium mine. Water Air Soil Pollut. 166:83-101.

Mullen, J.L., C. Weinig, and R.P. Hangarter. 2006. Shade avoidance and the regulation of leaf inclination in Arabidopsis. Plant Cell Environ. 29:1099-1106.

Neeser, C., A.R. Martin, P. Juroszek, and D.A. Mortensen. 2000. A comparison of visual and photographic estimates of weed biomass and weed control. Weed Technol. 14:586-590.

Ngouajio, M., G.D. Leroux, and C. Lemieux. 1999. Influence of images recording height and crop growth stage on leaf cover estimates and their performance in yield prediction models. Crop Protection 18:501-508.

Nilsson, H.E. 1995. Remote sensing and image analysis in plant pathology. Annu. Rev. Phytopathol. 15:489-527.

Olmstead, J.W., G.A. Lang, and G.G. Grove. 2001. Assessment of severity of powdery mildew infection of sweet cherry leaves by digital image analysis. Hort Science 36:107-111.

Olmstead, M.A., R. Wample, S. Greene, and J. Tarara. 2004. Nondestructive measurement of vegetative cover using digital image analysis. HortScience 39:55-59.

Radovich, T.J.K. and M.D. Kleinhenz. 2004. Rapid estimation of cabbage head volume across a population varying in head shape: A test of two geometric formulae. Hort Technology 14:388-391.

Rasmussen, J., M. Norremark, and B.M. Bibby. 2007. Assessment of leaf cover and crop soil cover in weed harrowing research using digital images. Weed Res. 47:299-310.

Roturier, S. and U. Bergsten. 2009. Establishment of Cladonia stellaris after artificial dispersal in an unfenced forest in northern Sweden. Rangifer 29: 39-49.

Stewart, A.M., K.L. Edmisten, R. Wells, and G.D. Collins. 2007. Measuring canopy coverage with digital image. Commun. Soil Sci. Plant Anal. 38:895-902.

Tackenberg, O. 2007. A new method for non-destructive measurement of biomass, growth rates, vertical biomass distribution and dry matter content based on digital image analysis. Ann. Biol. 99:777-783.

Thomas, D.L., F.J.K. daSilva, and W.A. Cromer. 1988. Image processing technique for plant canopy cover estimate. Trans. Amer. Soc. Agr. Eng. 31:428-434.

Trout, T.J., L.F. Johnson, and J. Gartung. 2008. Remote sensing of canopy cover in horticultural crops. HortScience 43:333337.

Tucker, C.J. 1980. A critical review of remote sensing and other methods for non-destructive estimation of standing crop biomass. Grass Forage Sci. 35:177-182.

Yang, C., J.H. Everitt, J.M. Bradford, and D. Murden. 2009. Comparison of airborne multispectral and hyperspectral imagery for estimating grain sorghum yield. Trans. Amer. Soc. Agr. Eng. 52:641-649.

Yang, C., T.X. Liu, and J.H. Everitt. 2008. Estimating cabbage physical parameters using remote sensing technology. Crop Protection 27:25-35. 